\title{
Methodological Practices in On-the-Job Learning Research
}

\author{
MARJOLEIN G. M. C. BERINGS*, ANJA J. DOORNBOS** \& \\ P. ROBERT-JAN SIMONS ${ }^{\dagger}$ \\ *Tilburg University, ${ }^{* *}$ University of Nijmegen, ${ }^{*}$ Utrecht University
}

\begin{abstract}
This paper compares and discusses aspects of methodological practices in on-the-job learning research. The focus is on contemporary research into on-the-job learning processes. Methodological practices refer to decisions of researchers in their research projects, to how they carry out the research, and how they report. This overview of methodological practices presents research instruments, on-the-job learning perspectives, paradigms, goals, researcher roles and quality and rigour considerations. The results show that, even though research in human resource development stems from different kinds of disciplines with their own data collection tools, there is nevertheless a rather limited variety in the instruments (questionnaires and interviews only) used for mapping the process of on-the-job learning. This is probably due to the implicit nature of most on-the-job learning processes. The paper proposes to apply research instruments from related research fields that could provide opportunities for future research. Combining instruments seems to offer fruitful opportunities for obtaining a more profound understanding of the process of onthe-job learning. The paper ends with a set of tentative guidelines for sound methodological practices in future research.
\end{abstract}

KEY WORDS: Methodological practices, methodological issues, on-the-job learning, paradigms, research instruments

\section{Introduction}

Key challenges in the mapping of on-the-job learning arise from the nature of such learning, which is frequently tacit. On-the-job learning is often not highly conscious, not intentional and not well planned, because it is opportunistic and closely integrated with work activities. Therefore, it is difficult to determine how learning processes take place (Marsick, 2003). Yet, good methodological practices, which are the decisions researchers take in their research projects as reflected in their design and report, are central to the success of published research (Rocco, 2003). Instrument design and other data collection tools are especially important in relatively new research fields such as on-the-job learning, which interests an increasing number of researchers as well as practitioners (Smith, 2003; D'abate et al., 2003; Rainbird et al., 2004). The aim of this study is to provide an overview of the variety of methodological 
practices in on-the-job learning research in order to identify tentative guidelines for future research addressing the process of on-the-job learning.

On-the-job learning, also referred to in the literature with terms such as workplace learning, work-based learning, work-related learning, informal learning and nonformal learning, plays a major role in initial and ongoing competence development. It implies human change or growth that occurs primarily in activities and contexts of work (Fenwick, 2001). Marsick and Watkins (1990) describe it as a situation where people go about their daily activities at work or in other spheres of life. This on-the-job learning can be very effective and necessary to develop professional and vocational knowledge and skills. Employees themselves believe that they have acquired most of their productive competence through their work - not through the educational system - and employers share this view. The basic idea of on-the-job learning is that it occurs outside the context of educational goals, and does not follow a formally organized learning programme or event. It happens within the context of day-to-day learning and development, and is therefore often spontaneous and integrated with work activities (Eraut, 2000; Marsick and Watkins, 1990). On-the-job learning is viewed as implicit or explicit mental and/or overt activities and processes, embedded in working and work-related performance, leading to relatively permanent changes in knowledge, attitudes or skills (adapted from Bolhuis and Simons, 1999, p. 16). Learning outcomes may vary from change to reinforcement, refinement or extension to learning something new. What people learn may be of immediate value to them: for example, how to do the job in a less stressful or exhausting way. At other times, what they learn could be related to the nature of the work itself (Billett, 2002). On-the-job learning concerns, for example, learning by routine, from direct or indirect experience, and in interaction with other people. It is the implicit or spontaneous character of the learning process that makes it difficult to examine, because workers may not be aware of their learning processes. In these cases, learning can be studied only retrospectively, by looking back from learning outcomes realized to the processes that must have taken place unconsciously and situations that have contributed to the learning outcome. Doornbos et al. (2004) differentiate between spontaneous and deliberate learning, based on the worker's intention to learn. They argue that spontaneous learning can occur when activities are performed with a goal other than learning in mind. The learning outcomes may refer to changes in knowledge, skills or attitudes as a result of such activities. They are typically unexpected and may therefore be described as byproducts, discoveries, coincidences or (sudden) realizations. The learner may also remain unaware of certain changes when, for example, reflection does not occur (Marsick and Watkins, 1992). Deliberate learning, in contrast, refers to those activities performed with the goal of learning in mind. The resulting changes in behaviour, skills and attitudes are planned, sought and sometimes even premeditated.

There is still much to explore about the modes and processes of individual on-thejob learning. We know little about the kinds of learning employees make use of, especially those that are spontaneous. Current themes and research directions address the social and situational aspects of learning through the on-the-job learning cultures, texts and discourses, identities and differences, equity and ethics in work and workplaces (Fenwick, 2001). Given the emergent interest in on-the-job learning, researchers put their efforts into collecting data on its processes to contribute to theoretical notions regarding this construct. Research instruments address different 
kinds of on-the-job learning, such as explicit and planned learning, emergent learning, self-directed learning, experiential learning, learning strategies, team learning, innovative learning, distance learning, etc. Some instruments are also used in intervention practices, for example when human resource developers apply instruments for diagnostic purposes and take into account individuals' different ways of learning in their daily practices, to improve the process of learning and consequently enhance performance. Examples of these instruments may be questionnaires, interviews, observations, documents (portfolios), visual methods (such as concept maps and diagrams) or personal narratives (e.g. logs and diaries) (Denzin and Lincoln, 2000).

With this growing body of research instruments and accompanying practices, the importance of accumulating the variety of instruments is increasing. Moreover, it seems important to formulate generic standards for methodological practices to be used in on-the-job learning research, since the current literature does not provide a systematic description of standards or guidelines for research. In this study, we will first propose and describe aspects of methodological practice. Then, we will provide an overview of the variety of instruments used to measure individual on-the-job learning processes and the accompanying methodological practices. The overview provides an insight into the contemporary state of research, and can serve as a starting point for further development. Next, to study what other instruments provide possibly useful opportunities for future research on individual on-the-job learning, we have examined literature covering a broader definition of on-the-job learning processes and literature on on-the-job learning outcomes. Based on our conclusions, we will formulate a set of guidelines of methodological practice, which is helpful in terms of quality improvement and for comparability reasons.

\section{Research Questions}

In this paper, methodological practices in on-the-job learning research are explored to gain an insight into their variety and qualities. These methodological practices may stem from different research paradigms. In line with Lincoln and Guba we choose not to follow one specific research paradigm, but rather to follow how various paradigms 'interbreed' and inform one another's argument (2000, p. 164). The aim is to provide an overview of this variety in order to identify tentative guidelines for future research addressing the process of on-the-job learning.

Therefore, the main research question of this study is twofold:

1. What is the variety of methodological practices in contemporary research on onthe-job learning?

2. What instruments not used in current research on on-the-job learning provide possibly useful opportunities for its future research?

\section{Variety of Paradigms}

A paradigm can be defined as a philosophical template or framework that guides the production of knowledge (Kuhn, 1962). It concerns beliefs about what can be known about the world and how we can come to know it. Within each paradigm, several research methodologies are possible, each drawing on a number of methods or 
techniques for data collection and interpretation (Lincoln and Guba, 2000). The explicit or implicit paradigm and strategy are related to the applied methodological practices. A useful categorization of paradigms could be based on a combination of Melles's (1999) and Lincoln and Guba's (2000) categorizations, and includes the (post-)positivistic, interpretative, critical and participatory approach. In our description of the variety of methodological practices in on-the-job learning research, we will often follow Lincoln and Guba (2000) in a more rough division of social scientists: classical researchers and new-paradigm inquirers. Classical researchers are scientists from the (post-)positivistic paradigm and new-paradigm inquirers from the other paradigms mentioned above. Classical researchers have foundational ideas that are discovered and imply certain final, ultimate criteria for testing the truth. New-paradigm researchers have non-foundational ideas, and argue that there are no such criteria, only those that we can agree upon at a certain time and under certain conditions; criteria that are negotiated (Lincoln and Guba, 2000).

\section{Aspects of Methodological Practice}

Methodological practice can be used as a concept to describe decisions researchers take in their research projects, how they carry them out and report on them. Therefore, in our view, methodological practice goes beyond the researcher's decisions to use a particular research method or instrument and refers to the operationalization of research concepts, research goals, researcher roles and how to maintain rigour and quality (inspired by Lincoln and Guba, 2000). These decisions are dependent on the underlying paradigm. Furthermore, methodological practice does not include only the decisions researchers take, but also how these decisions are reflected in their design and report.

The next section describes the aspects of methodological practice distinguished above.

\section{Operationalization of the Research Concept}

Researchers investigating on-the-job learning processes have different perspectives in their operationalization of the research concept. Some focus on deliberate learning only; some focus on spontaneous learning, too. They focus on, for example, styles, activities, strategies, tactics, behaviours, orientations and approaches. According to Berings and Poell (2005), an on-the-job learning style is the tendency to use a certain combination of implicit and explicit learning activities that a person is able and likes to engage in on the job. The person may use a different combination of learning activities in each different situation. This particular combination is called the actualized learning strategy. Dalton (1999) describes learning tactics as the behaviours that individuals have reported using when engaged in the task of learning. Learning orientations refer to how people think about learning. These indicate a cross-situational consistency in approach to learning (Entwistle, 1988). A learning approach can be described as learning processes that stem from a learner's perception of a particular learning situation, and as being influenced by their personal characteristics (cf. Biggs, 1988). All the above perspectives describe a rich variety of on-the-job learning processes and can focus on both mental and overt, and both spontaneous and deliberate, learning activities. 


\section{Research Goals}

The goals of research can be to predict, explain, explore, describe or perform action (Dane, 1990). New-paradigm inquirers are increasingly concerned with singular experiences. Classical researchers generalize their findings towards their particular research population (Lincoln and Guba, 2000).

Classical researchers are mostly focused on prediction or explanation. Predictive research identifies relationships that enable us to speculate about one thing by knowing about other things. Explanatory research involves examining a cause-effect relationship between two or more phenomena. It is used to determine whether or not an explanation (a cause-effect relationship) is valid or which of two or more competing explanations is the more valid.

New-paradigm researchers have other research goals. Critical theorists and interpretativists are mostly directed towards explorations and descriptions. Exploratory research involves an attempt to determine whether or not a phenomenon exists. Descriptive research involves examining a phenomenon to define it more fully or to differentiate it from other phenomena. The goal of participatory researchers is action. Action research refers to research conducted to solve a social problem. Marsick and Watkins (1990) describe it as a cyclical process by which a group of people jointly identify a problem, experiment with a solution, monitor the results, reflect on the process and use the resultant information to reformulate the problem, which may lead to another cycle of research.

\section{Researcher's Role}

The researcher's role can be described in terms of interaction with others involved in the research project (Lincoln and Guba, 2000). The inquirer posture of a classical researcher is that of an informant of decision-makers, policy-makers and change agents. Classical researchers merely control their research and deny their own influence. In contrast, new-paradigm inquirers admit their influence and report about this (Lincoln and Guba, 2000). They share control with the participants. Interpretativists are passionate participants, who are facilitators of multi-voice reconstruction, share their control of the research and are involved with the participants. A third role that can be distinguished is the role of an activist, where the participating researcher's primary voice is manifest through conscious self-reflective action, and his or her secondary voice is manifest in illuminating theory through which shared control of the research becomes salient in varying degrees. Lincoln and Guba (2000) do not describe the role of critical researchers. In our view, critical researchers can be described as reflexivists, who continuously elucidate the means by which their own and respondents' value suppositions guide the framing of theory and fact. Critical researchers do not take for granted and reproduce, but reflect on dominant institutions and ideologies as a way to emancipate from frozen social and ideational patterns (Alvesson and Sköldberg, 2000).

\section{Maintaining Rigour and Quality}

Classical researchers perform mainly quantitative research, and new-paradigm inquirers perform mainly qualitative research (Lincoln and Guba, 2000). However, 
within each paradigm, mixed methodologies may make perfectly good sense (Guba and Lincoln, 1981; Lincoln and Guba, 2000). Instruments that can be used are, for example, questionnaires, interviews, observations, documents (portfolios), visual methods (such as concept maps and diagrams) or personal narratives (e.g. logs and diaries) (Denzin and Lincoln, 2000). The underlying paradigm may have a major impact on how researchers maintain the quality and rigour of their research, that is, what effort they put into achieving credibility in design, analysis and report. Significant aspects will be briefly mentioned here.

Classical researchers can use conventional benchmarks of rigour (validity, reliability and objectivity). In our review, we used the definitions of Messick (1980) and Allen and Yen (1979). We will discern: content, construct and criterion validity. Furthermore, we distinguish test-retest reliability, alternate form reliability and internal consistency. Objectivity refers to procedures for minimizing investigator bias.

New-paradigm researchers can maintain rigour and quality by validity, generalizability (Maxwell, 2002), rigorous methods and authenticity (Patton, 2002; Lincoln and Guba, 2000). Maxwell (2002) provides a typology of understanding and validity in qualitative research including descriptive validity (factual accuracy of participants' accounts), interpretative validity (inferences drawn from participants' actions and words; the participants' perspectives in terms of intention, cognition, belief, affect and evaluation), theoretical validity (a theory that the researcher brings to, or develops during the study of some phenomenon in terms of concepts or categories and the relationships thought to exist between these concepts) and evaluative validity (application of an evaluative framework to the objects of study). Yin (1994) offers a very straightforward protocol approach for case-study research, emphasizing field procedures, case-study questions and a guide for reporting. Yin claims such steps are a major tactic for increasing the reliability of the research endeavour. Generalizability refers to the extent to which one can extend the account of a particular situation or population to other persons, times or settings than those directly studied. Rigorous methods yield high-quality data that are systematically analysed with attention to issues of credibility such as searching for rival explanations, explaining negative cases and triangulation. Authenticity is the 'reflexive consciousness about one's own perspective, appreciation for the perspective of others, and fairness in depicting constructions in the values that triggered them' (Patton, 2002, p. 546). In our view, this refers to the consideration of investigator effects, such as training, experience, status and also representation of self.

In the next section of the paper, we describe how we reviewed the variety of all above mentioned aspects of methodological practice in contemporary research on on-the-job learning. Finally, we will discuss what can be learned from this for future research.

\section{Procedure}

\section{Variety of Methodological Practices}

To identify the variety of methodological practices in contemporary research on onthe-job learning, a four-step procedure was used to select instruments to be included in our overview. First, the instruments, gathered unsystematically in our research 
projects during the last two years, served as a starting point for the exploration. Second, we thought about descriptions under which on-the-job learning instruments could be categorized, such as on-the-job learning, workplace learning, workbased learning, work-related learning, informal learning, non-formal learning, vocational or occupational learning, skill development, growth or acquiring know-how, competence, ability, mastery and expertise in combination with descriptions of instruments, such as diary, journal, log, narrative, diagram, picture, chart, questionnaire, inventory, interview, critical incident, portfolio and concept maps. These descriptions were used in searching ERIC, PsychINFO and ABI/Inform. Third, we conducted a hand search of each issue (1998-2004) of six major journals on this topic: Adult Education Quarterly, Human Resource Development International, Human Resource Development Quarterly, Journal of Workplace Learning, Lifelong Learning in Europe and Studies in Continuing Education. Fourth, we examined reference lists of articles to identify additional, relevant sources. The studies of on-the-job learning processes and the accompanying methodological practices that will be included in the overview had to meet six selection criteria, to review a congruent set of studies sharing similar features. The studies should:

1. measure the process, and not the product, of on-the-job learning;

2. be applied in employee learning, that is learning confined to the context of an occupation;

3. measure individual employee learning (in a social context), and not group or organizational learning;

4. include empirical data collection and analysis;

5. be clearly described in published material;

6. contribute to the variety of instruments and accompanying methodological practices, and not to the quantity of instruments.

Studies needed to fulfil all of the criteria above to be selected for the overview.

In line with the above discussion, we describe the methodological practices of the studies included in the overview in terms of the specific instruments used, their perspective on on-the-job learning, the research goals, the researcher's role, the subjects examined and how rigour and quality were maintained. This latter characteristic is further divided into method description, validity, reliability and objectivity for quantitative studies, and method description, validity, evaluation of the instrument and authenticity for qualitative studies. Furthermore, we included instrument samples and descriptions of the subjects.

This description of methodological practice follows the AHRD Standards on ethics and integrity (Russ-Eft et al., 1999). These standards suggest that 'HRD professionals who develop and conduct research with tests and other assessment techniques use research procedures and current professional knowledge for test and research design, standardization, validation, reduction or elimination of bias, and recommendations for use' (ibid., p. 8).

The tables present information explicitly described by the authors in normal print. Information we were able to infer only indirectly appears in italics. When the information is absent, the table cell remains blank. 


\section{Other Instruments}

To study which other instruments provide possibly useful opportunities for future research on on-the-job learning processes, we extended the first and second items of our selection criteria. The first criterion was extended to include learning outcomes as a result of on-the-job learning processes, descriptions of work activities and experiences in which employees learn. The second criterion was extended to include student learning in apprenticeships and employee learning which is not job related. Our third, fourth, fifth and sixth criteria were kept unchanged.

\section{Findings}

\section{Variety of Methodological Practices}

The variety of methodological practices in contemporary research on on-the-job learning is listed in the overviews of Table 1 and 2. The overview shows variety (examples in all categories found), and is not meant to be all-embracing or representative. In general, many studies did not report on all aspects of methodological practice. Especially, information as to quality and rigour was often incomplete. Appendices 1 and 2 present instrument samples and descriptions of the subjects examined.

We found only questionnaires and interviews meeting the initial selection criteria, no other kinds of instruments. Researchers report the qualities of the instruments differently according to the kind of instrument.

The perspective on on-the-job learning applied in research conducted with questionnaires addresses deliberate learning in terms of strategies, behaviours and approaches, as can be seen in Table 1. Deliberate learning is studied in specific learning events or as a relative stable set of activities that employees apply in all kinds of situations. Only the questionnaire of Megginson (1996) covers spontaneous learning (as well as deliberate learning). Research goals in the questionnaires vary from exploration to explanation. In five out of six surveys, the researcher performs the role of an informant, whereas in one case (learning tactics inventory) a passionate participant role was identified. As far as reporting on quality and rigour is concerned, most authors inform the reader on internal consistency of the different scales or on the intercorrelations between items within one scale.

Perspectives on on-the-job learning in the interview studies vary from directed and self-initiated learning (projects) to ubiquitous activity in work that is sometimes inseparable from learning. Thus, spontaneous learning is addressed more often in interview studies than in surveys. Interview goals are to describe and/or to explain, with the exception of one interview that was also pursued to help people to take care of their own development. The researcher's role is mostly that of a passionate participant, but informant, reflexivist and activist roles were also found. Interviews are sometimes pilot-tested, and are either semi-structured or follow a critical incident approach, as can be seen in Table 2. Remarks about interpretative and theoretical validity and generalizability were often reported. In contrast, evaluating the method or the authenticity of the study was less frequently found. 
Methodological Practices in On-the-Job Learning Research 341

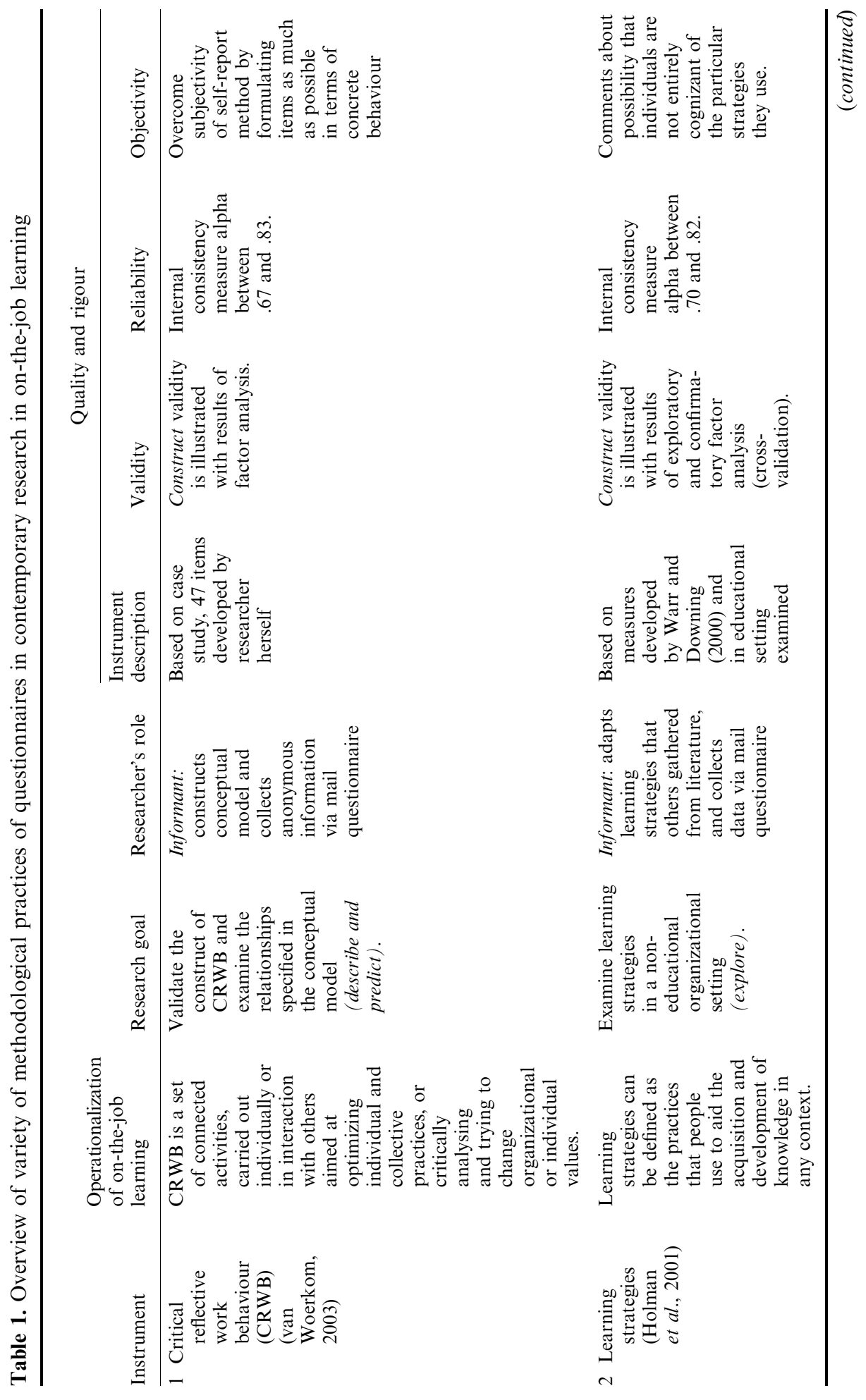


M. G. M. C. Berings et al.

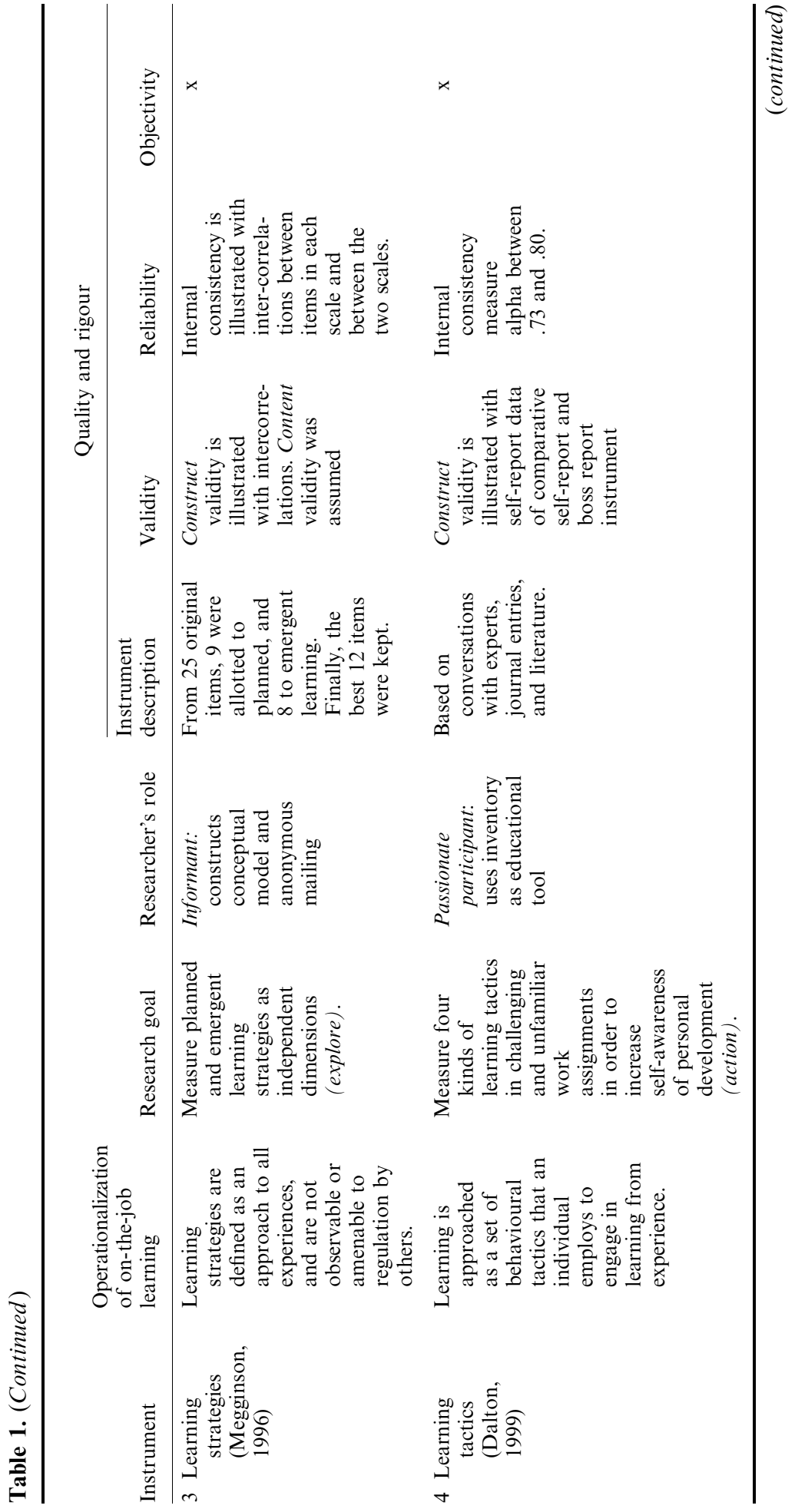




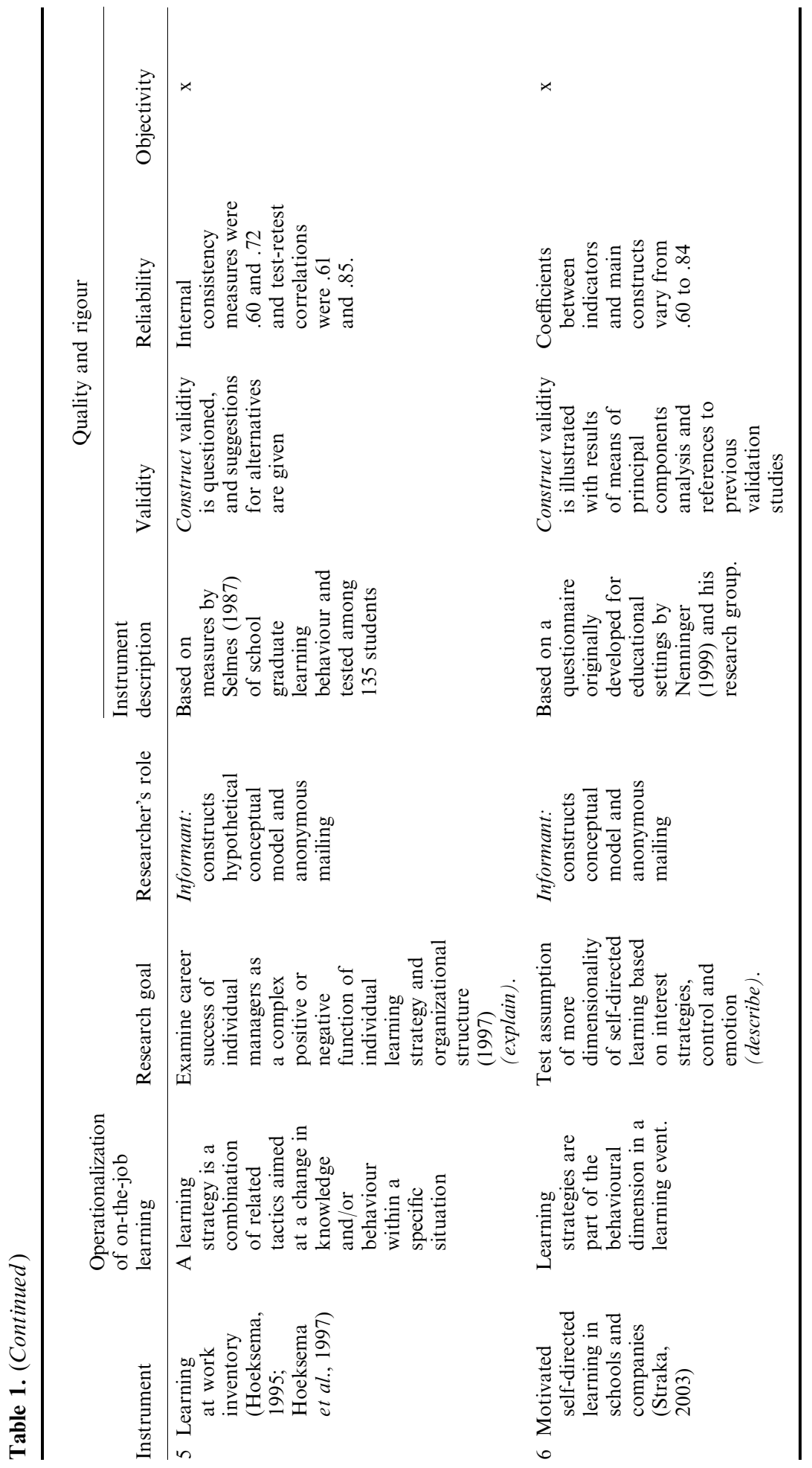


344 M. G. M. C. Berings et al.

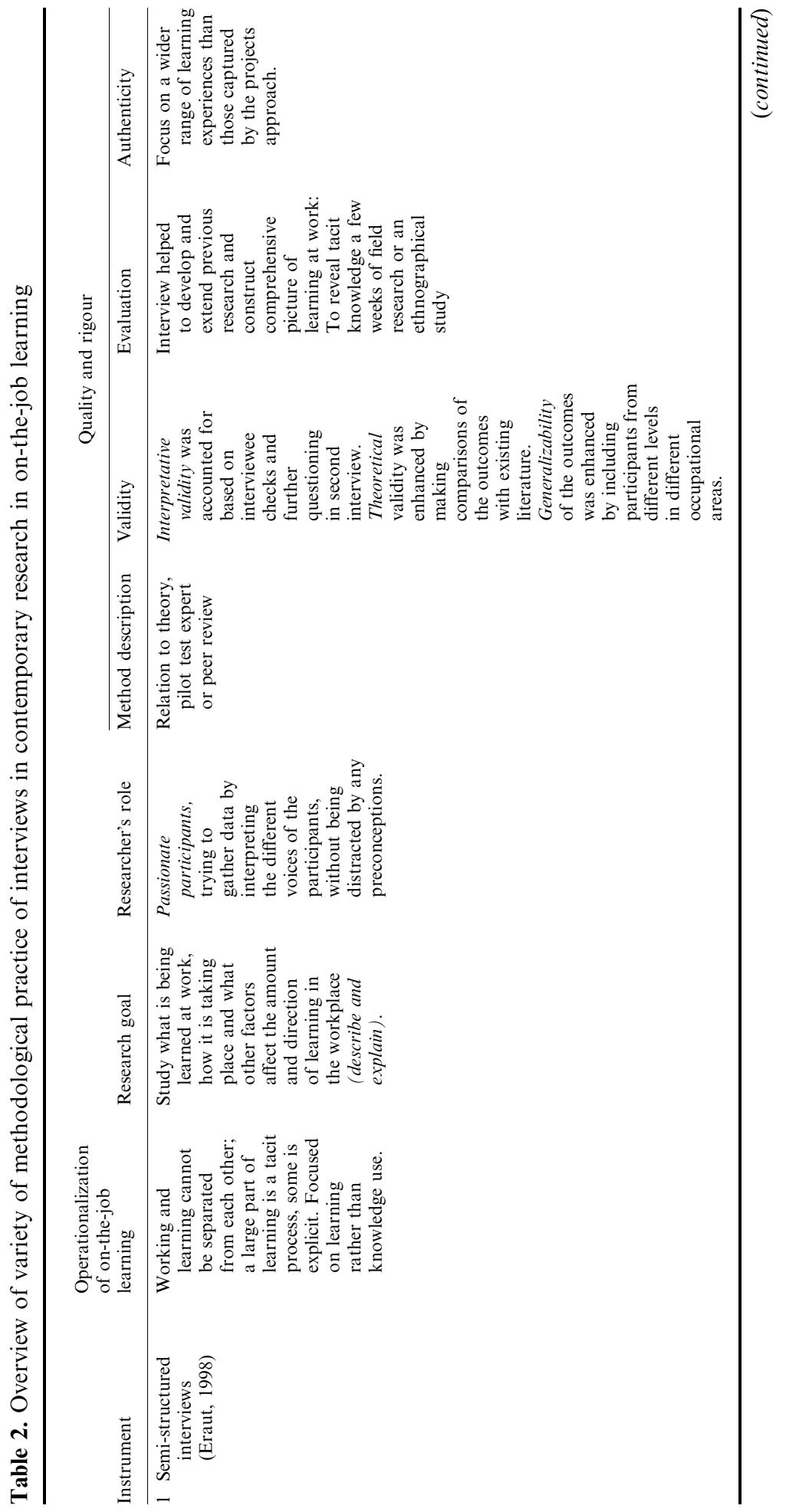




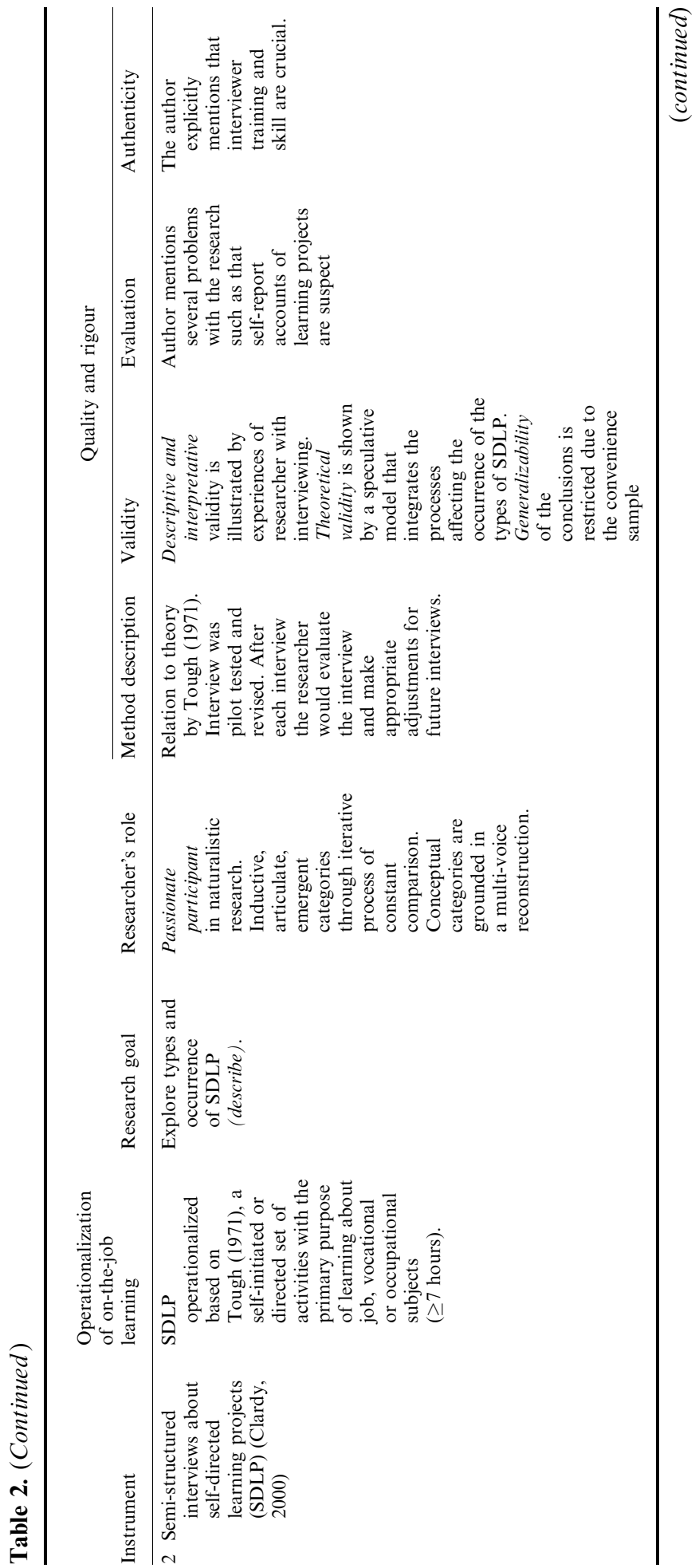


346 M. G. M. C. Berings et al.

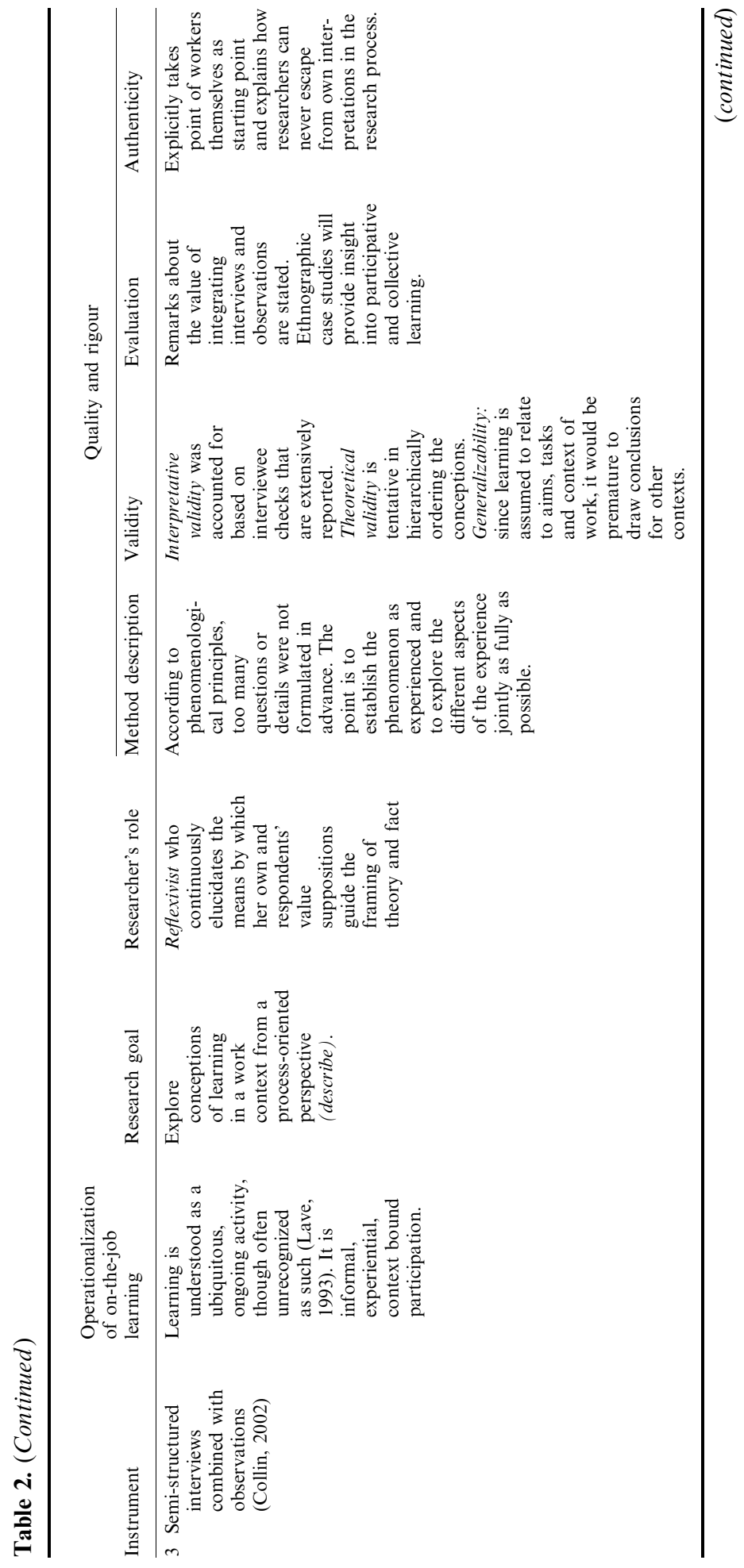




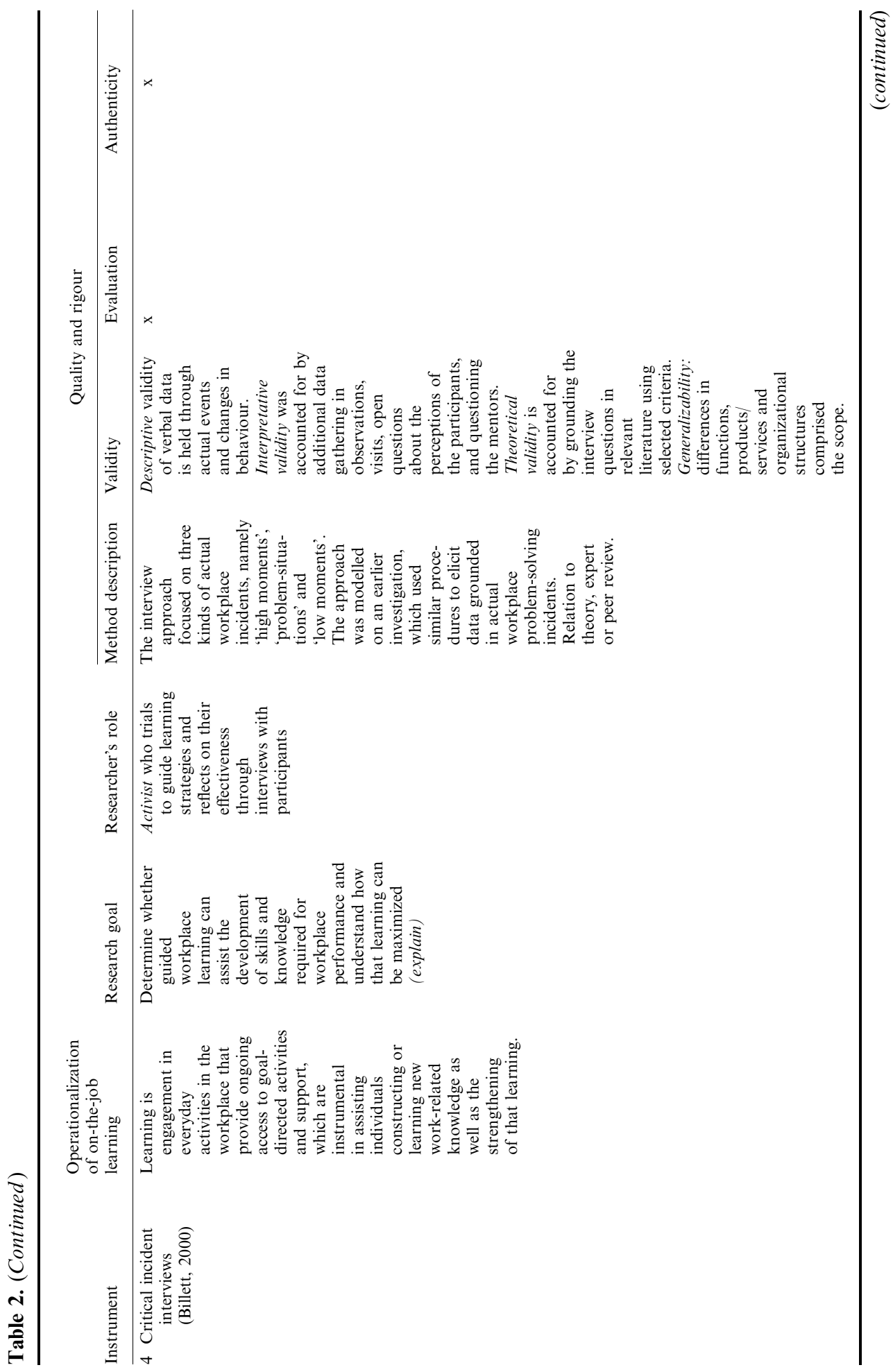


348 M. G. M. C. Berings et al.

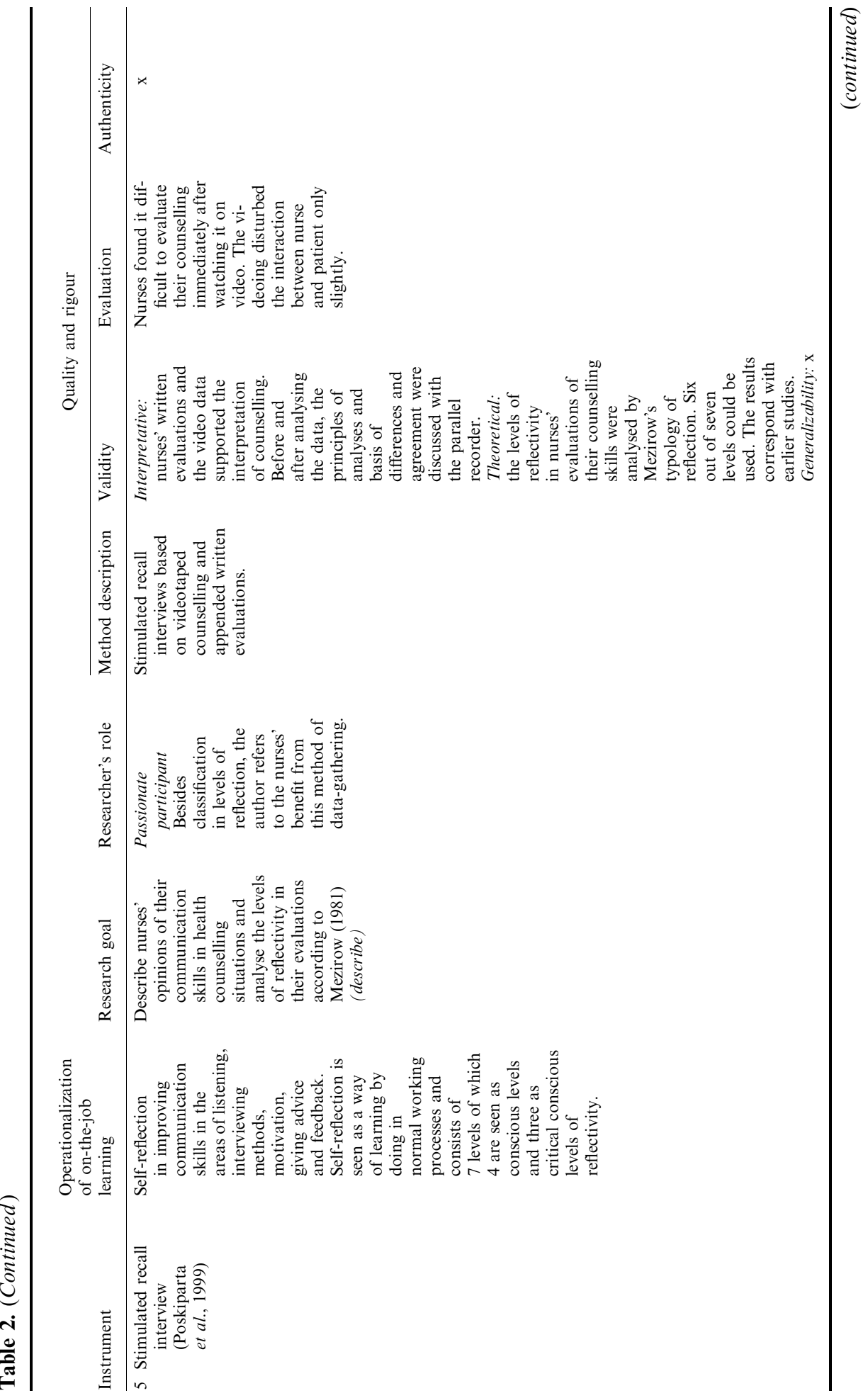




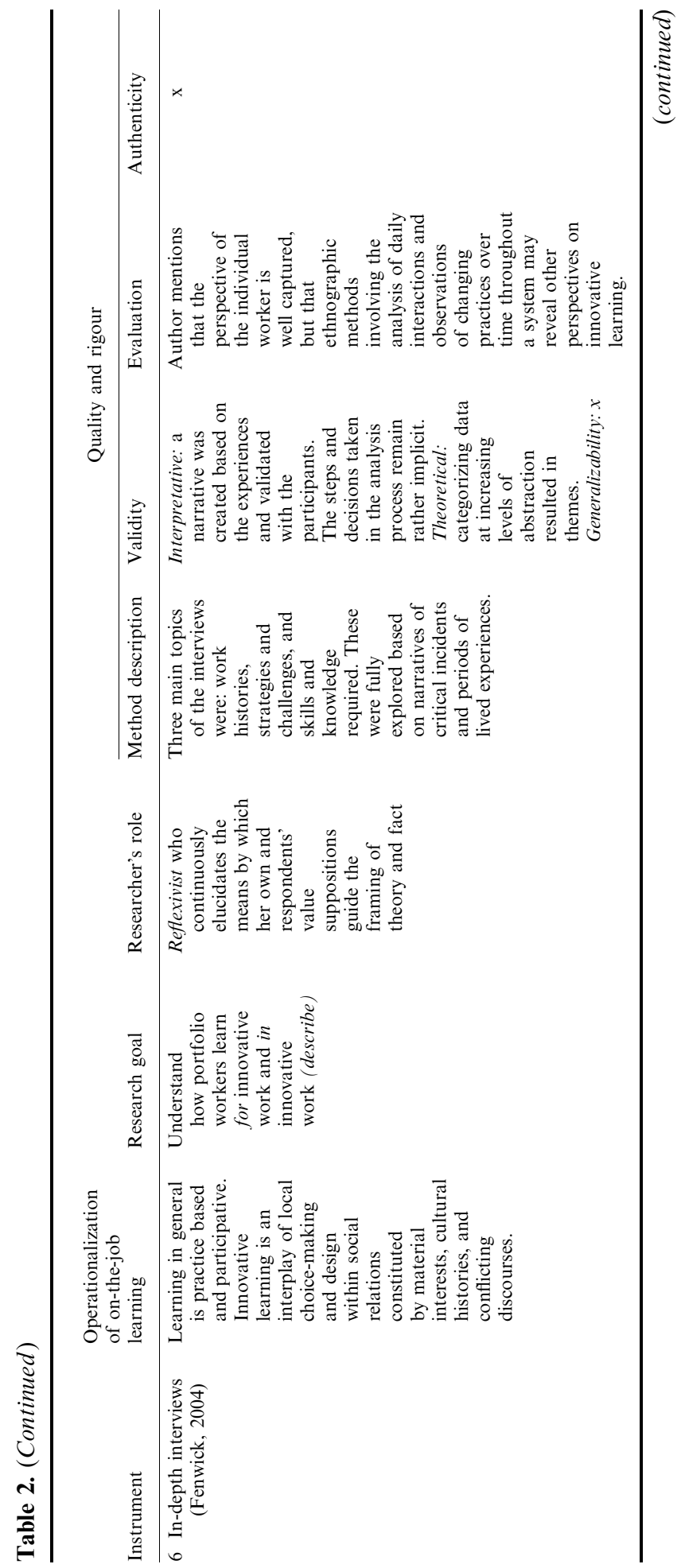




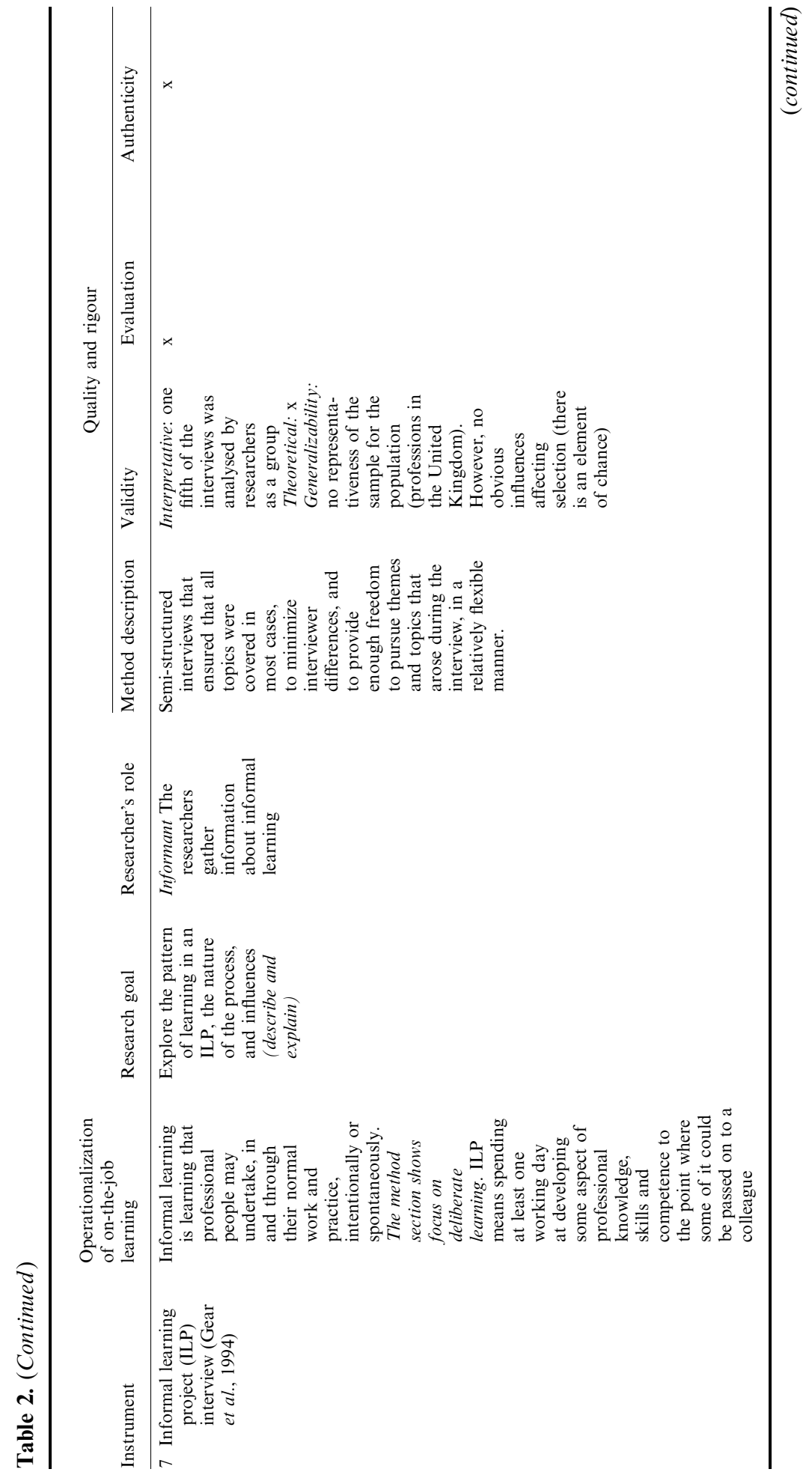




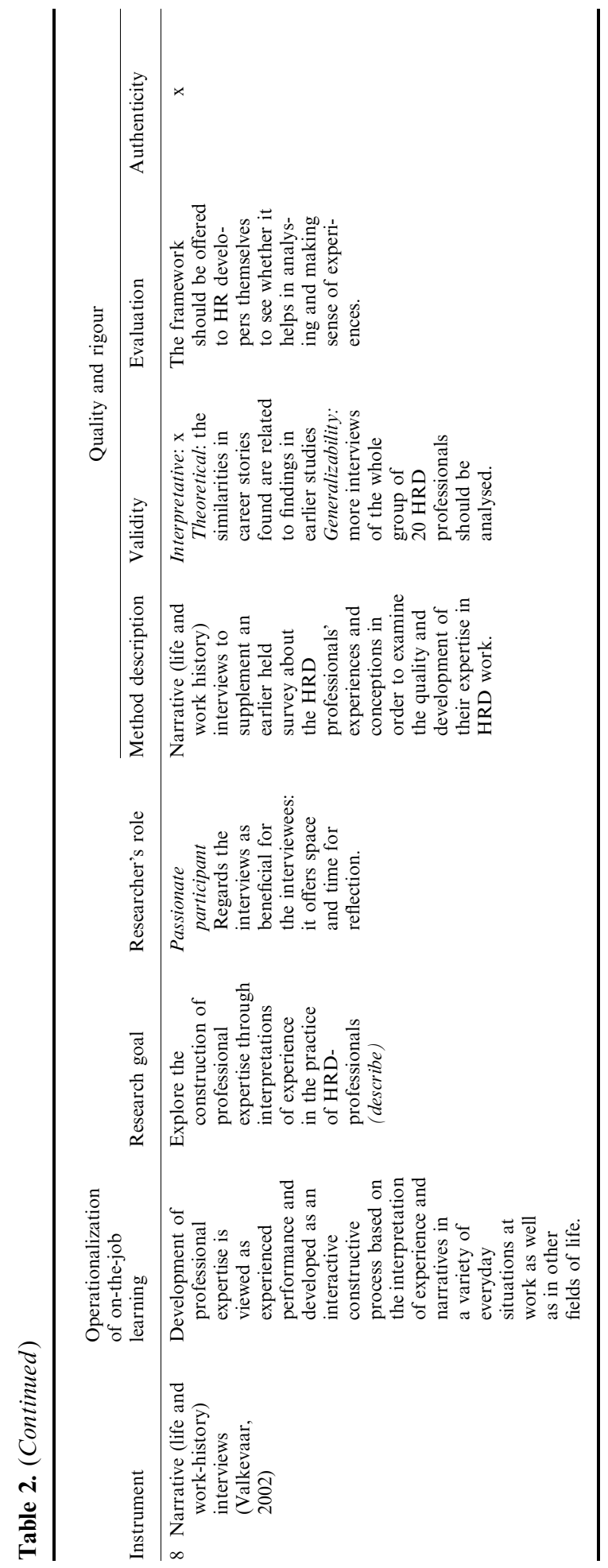


The four paradigms described above, one classical and three new, could not be unambiguously inferred from the reports. It appeared that paradigms do indeed interbreed on a methodological level (Lincoln and Guba, 2000). Moreover, in most cases, scholars were not explicit about the underlying paradigm. Thus, no data are reported on this issue in the tables.

Most of the information in the tables comes from the researchers themselves, some could be indirectly inferred from the reports (reported here in italics) and some is just lacking. The researchers' roles, in particular, could only be inferred indirectly, and information on quality and rigour was often lacking and could not be inferred from the reports. Researchers using questionnaires do mostly report about the validity and reliability of the instrument afterwards, whereas researchers using interview instruments mainly focus on rigour and quality beforehand.

\section{Instruments for Future Research}

Instruments from related literature provide possibly useful opportunities for on-thejob learning research in the future. Literature focusing on the (re)design of work, changing environmental conditions or employee competencies or pursuing improvement of work outcomes is relevant, especially for research goals that relate to the innovative efforts of human resource departments in stimulating on-the-job learning.

Research instruments addressing on-the-job learning in relation to the various work-related activities employees carry out, are, for example, observations of managers' work activities (Mintzberg, 1970), structured diaries of bank apprentices activities (Noß, 2000), concept maps of adult learners' activities (Stevens, 1997) or photographs and drawings (Daniels, 2003). Faurfelt and Wichmann-Hanssen (1999) combined observations and diaries with interviews in a study of learning in apprenticeships to identify encouraging and inhibiting factors for learning processes in junior doctors' continuing education at a surgical ward. Observations focused on the interaction between the task, the junior doctor, the teacher and the work environment. In the diaries, the junior doctors recorded what they believed they had learned and how they had experienced the learning situation. Carson and Longhini (2002) reported on a study in which diaries and discussions were combined. She used a learning diary, containing narratives of learning Spanish during an exchange in a Spanish-language country. The analyses of these narratives followed a pre-formatted structure of language-learning strategies, and a second researcher read the diary, discussed issues and questioned the diary-writer. However, diaries may also be used in isolation, for example, when Reimers (1971) analysed his own learning diary, in which he mapped his progress in a work-related course. Diary studies seem to be useful in understanding how people learn in interaction with their social context, and in relation to what they have learned, whether this is being analysed in a pre-structured manner or not, by the writers themselves or a researcher, or in combination with other data-collection tools. Alternatives to diaries are photographs and drawings, such as Daniels (2003) used to strengthen her inquiry into women's capacity for leadership and community building in South Africa with interviews and observations. She gave her participants a disposable camera to take pictures of their home environment, family and life. Through the photographs the researcher gained 
a better understanding of the participants' visibility, strengths and potentials in community building. With this data-collecting method, the decision-making power shifted away from the researcher and more to the participants. They served as elaborators of verbal dialogue and became rich sources of data on the participants' feelings about the topic of interest 'community' and encouraged collaborative inquiry.

Studies of learning products are another research track that provides potentially useful instruments for future research on on-the-job learning. For example, Brown (2002) reports on portfolios of what adult students (re-) entering college have learned from their work experiences. Portfolios provide an insight not only into what people have learned, but also into how they have learned, through substantial descriptions of the experiences and the learning processes.

\section{Conclusions and Discussion}

The main conclusion concerning the first research question is that in contemporary research into on-the-job learning, the research instruments used to map on-the-job learning processes are questionnaires and interview guides only. Inspired by Lincoln and Guba (2000), we investigated the rather limited variety of methodological practices in terms of the underlying paradigms, the operationalization of the research concept of on-the-job learning, the research goals, the researcher's role and how to maintain rigour and quality. The main conclusions concerning the variety in these aspects of methodological practices can be formulated as follows.

From the publications, the research paradigms adhered to could not be unambiguously inferred. It appeared that paradigms interbreed on a methodological level (Lincoln and Guba, 2000). In research into on-the-job learning many different operationalizations of the research concept are used. Further, the range of width across which the concept is investigated is large. However, it is currently recognized by many scholars that learning at work is best understood by taking different perspectives into account: terms of the nature of the task itself, the cultural and social relations that characterize the workplace and the experiences and social world of the participants (Illeris, 2002; Billett, 2002). The publications we investigated use questionnaires and interview guides for a detailed investigation of specific aspects of learning processes for the goals of describing, explaining or exploring. Further, one questionnaire study was aimed at predicting and one questionnaire study was aimed at action. The researchers' roles could be inferred only indirectly from the publications. In the studies using questionnaires, the researchers are mostly informants. Only Dalton (1999) has the role of a passionate participant in her study on learning tactics, in which she uses the questionnaire as an educational tool. The variety of researcher's roles in the studies using interview guides is higher: we found an informant, passionate participants, reflexivists and an activist.

Information on quality and rigour is often lacking, especially in the interview studies. Billett (2000), for example, used the same (modelled) interview strategy on several occasions, but does not report on the reason for or type of adjustments. Reliability can be achieved by using detailed protocols and by checking for generalization. We do not want to suggest that the absent information is due to 
inadequate thinking on these aspects of methodological practice. It may result from incomplete reporting (in books) or limited space in articles. Maxwell's (2002) typology of validity seems a usable approach to get more information on validity. It stands out that researchers using questionnaires in most cases do afterwards report on the validity and reliability of the instrument, whereas researchers using interviews mainly focus beforehand on controlling rigour and quality. Sometimes, triangulation is used (see, e.g., Faurfelt and Wichmann-Hanssen, 1999). We believe that validity and reliability should become a more important concern for new-paradigm researchers. On the other hand, triangulation may be a good option for researchers using questionnaires too, especially in the case of investigating implicit on-the-job learning that seems difficult to catch. It can then be checked if different instruments agree with each other or, at least, do not contradict one another (Miles and Huberman, 1994). Van Woerkom advised as follows: 'Further research could focus on inter-rater reliability, and on the possibilities that the 360-degree feedback method offers to increase the validity of the instrument, contrasting self-ratings with ratings of colleagues and immediate managers' (2003, p. 170). Further, Holman et al. concluded: 'Research needs to be conducted in a wider range of learning strategies and such studies would benefit from being multi-method and not relying on selfreport questionnaire-based measures as it is possible that individuals are not entirely cognizant of the particular strategies they use' (2001, p. 680). Observing what people actually do in addition to inquiring what they say they did may therefore raise rigour and quality of the data in terms of validity.

A reason for the observed preference of researchers into on-the-job learning for the use of questionnaires and interview guides may be that these instruments are commonly applied in scientific research, often standardized and easier to report on compared to instruments that are less common. On-the-job learning is a relatively new field of study that benefits from available instruments. Furthermore, so far onthe-job learning has been studied in the field with its practical time constraints as opposed to in laboratory settings. Researchers probably use only interviews and questionnaires due to the implicit nature of most on-the-job learning processes. These implicit processes can be identified only when reflection on these processes is stimulated. In observations, diagrams, personal narratives, etc., probably only the explicit learning processes would become visible.

The advantage of using questionnaires is that large groups of employees can be reached. The disadvantage is that on-the-job learning is measured restrictedly in terms of approaches, activities, and strategies and questionnaires do not provide insight into learning histories and meaning making in experiences or spontaneous learning. We can conclude that in questionnaires deliberate learning, whether it is mental or overt, is satisfyingly measured, but that it is more difficult to measure spontaneous learning using questionnaires, since one cannot ask individual followup questions in questionnaires. The advantage of using interview guides is that they can better provide insight into tacit processes and interpretations of experiences. This means, in our view, that employees are better recognized in their personal learning stories. The disadvantage is that it is difficult to reach a large group of people.

To answer the second research question, other instruments not used in current research on on-the-job learning that provide potentially useful opportunities for 
future research on on-the-job learning processes are observations, diagrams, personal narratives and documents, often utilized in combination with interviews and/or questionnaires. In mapping learning outcomes and work experiences, these instruments are useful as a trigger for making explicit the learning processes embedded in these experiences, in interviews and/or questionnaires. This indirect questioning of the process may solve some practical problems related to researching on-the-job learning, such as the difficulty of talking about learning processes at work, often an unusual topic to share experiences about. Other difficulties are the willingness to disclose sensitive experiences in which mistakes were made or the employees' feelings of insecurity about what experiences are relevant or interesting to the research. Furthermore, the instruments themselves may create a 'need' to talk about on-the-job learning since they direct the employees' attention to it when putting down their experiences in narratives or diagrams. It is expected that this should contribute to a better understanding on the part of both participants and the researcher into experiences relevant to on-the-job learning processes.

We found examples of studies that used observation techniques to investigate communication patterns in workplace situations (e.g. Wheelan et al., 1994; Kubo et al., 2001). Observation techniques might offer opportunities for measuring interpersonal learning processes, even though communication patterns are a specific way of learning in which only knowledge sharing is being studied. These overt activities can be more easily observed than mental learning activities.

A final possibility for future research is inspired by research on collective learning. As noted earlier, there is a growing interest in how individual learning contributes to the larger collective of the organization. Barker and Neaily (1999) examined how collective learning (innovation) could be facilitated by starting with the individual awareness of what had been learned by explicating this in learning logs and later discussing this with fellow automotive manufacturing employees. For example, collective learning through knowledge sharing is studied through observations of communication patterns at a bank (Kubo et al., 2001) or conference session documents of professionals from a variety of fields (Wheelan et al., 1994).

This study does not have the ambition to review the methodological practices of the entire body of contemporary research on on-the-job learning. Instead, we have systematically searched the available literature, and selected cases representative of certain kinds of practice. Similar reports were not selected. The database, therefore, is not a representative overview of all the research available, but of the kinds of research instruments in use. It should be noted that this might have influenced the findings of this study.

With the growing body of research instruments and accompanying practices, the importance increases of listing the variety of instruments. Moreover, it seems important to formulate generic standards for methodological practices in on-the-job learning research, since the current literature does not provide research standards or guidelines.

\section{Guidelines for Future Research}

In this final section, we formulate a tentative set of guidelines for future research on methodological practices in on-the-job learning research. One might object that 
identifying general guidelines for rigour and quality in methodological practice is in contradiction with our attempts to connect paradigms and methodological practice. Yet, some important general guidelines can be identified whether researchers have a classical or a new-paradigm approach. The main underlying idea behind most of our guidelines is that researchers should be explicit about all aspects of methodological practice as conceptualized above.

Based on the overview of methodological practices found and in line with the ideas of Lincoln and Guba (2000), we recommend that future on-the-job learning researchers:

1. pay attention to on-the-job learning in terms of the nature of the task itself, the cultural and social relations that characterize the workplace and the experiences and social world of the participants;

2. explicitly account for the relationships between the underlying paradigm and all aspects of the methodological practice used;

3. try to triangulate by using different kinds of data-collection methods that provide different perspectives on on-the-job learning (e.g. observations provide insight in current activities and interviews provide insight in stories of the past and in people's intentions);

4. in addition, use other instruments, such as observations, diagrams, personal narratives and documents, besides questionnaires and interviews to study the complex interplay of the learner's deliberate and spontaneous internal process and the social environment;

5. be explicit about the role they themselves play in the research (informant, passionate participant, activist, reflexivist);

6. describe how they maintain rigour and quality, before, during and after data gathering.

a. For questionnaires, we propose that future researchers describe not only the internal consistency (coefficients alpha) of the questionnaires, but also: a) the process of item construction and selection, including the use they make of pre-existing instruments; b) example items for each subscale; c) how the data gathered with the questionnaire were analysed, d) pilot research they did to test the reliability and validity of the instrument and e) indications of validity (e.g. content validity, construct validity and criterion validity).

b. For interviews, we propose that future researchers describe not only the interview questions used, but also: a) whether and how they were used flexibly depending on the answers received; b) how the questions were constructed and pre-tested and with whom; c) how the interview data were analysed, d) what selections of interview data were made and how, and e) indications of validity (descriptive, interpretative, theoretical and/or evaluative validity and generalizability, cf. Maxwell, 2002).

One final guideline we would like to propose, not directly following from our findings, but from new-paradigm researchers' literature (e.g. Alvesson and Sköldberg, 2000), is to use the opinions of subjects more explicitly. Respondents could, besides answering, also evaluate the questionnaires and interviews. 
With this paper, we hope to contribute to the quality of future on-the-job learning research, by stimulating researchers in this field to take different perspectives on onthe-job learning into account: terms of the nature of the task itself, the cultural and social relations that characterize the workplace and the experiences and social world of the participants. Further, we hope to encourage them to be more explicit on their use of methodological practice and to use a larger variety of instruments.

\section{References}

Allen, M. J. and Yen, W. M. (1979) Introduction to Measurement Theory (Monterey, CA: Brooks/Cole). Alvesson, M. and Sköldberg, K. (2000) Reflexive Methodology: New Vista's for Qualitative Research (London: Sage).

Barker, M. and Neailey, K. (1999) From individual learning to project team learning and innovation: a structured approach, Journal of Workplace Learning, 11, pp. 60-7.

Berings, M. G. M. C. and Poell, R. F. (2005) Measuring on-the-job learning styles, British Journal of Occupational Learning, 3, pp. 3-12.

Biggs, J. B. (1988) Approaches to learning and to essay writing, in: R. R. Schmeck (Ed.) Learning Strategies and Learning Styles, pp. 185-228 (New York: Plenum).

Billett, S. (2000) Guided learning at work, Journal of Workplace Learning, 12, pp. $272-85$.

Billett, S. (2002) Workplace pedagogic practices: co-participation and learning, British Journal of Educational Studies, 50, pp. 457-81.

Bolhuis, S. and Simons, P. R. J. (1999) Leren en Werken (Learning and Working) (Deventer, The Netherlands: Kluwer).

Brown, J. (2002) Know thyself: the impact of portfolio development on adult learning, Adult Education Quarterly, 52, pp. $228-45$.

Carson, J. G. and Longhini, A. (2002) Focussing on learning styles and strategies: a diary study in an immersion setting, Language Learning, 52, pp. 401-38.

Clardy, A. (2000) Learning on their own: vocationally oriented self-directed learning projects, Human Resource Development Quarterly, 11, pp. 105-25.

Collin, K. (2002) Development engineers' conceptions of learning at work, Studies in Continuing Education, 24, pp. $133-52$.

D'abate, C., Eddy, E. R. and Tannenbaum, S. I. (2003) What's in a name? A literature based approach to understanding mentoring coaching, and other constructs that describe developmental interactions, Human Resource Development Review, 2, pp. 360-84.

Dalton, M. (1999) Learning Tactics Inventory: Facilitators Guide (San Francisco, CA: Jossey-Bass/ Pfeiffer).

Dane, F. C. (1990) Research Methods (Pacific Grove, CA: Brooks/Cole).

Daniels, D. (2003) Learning about community leadership: fusing methodology and pedagogy to learn about the lives of settlement women, Adult Education Quarterly, 53, pp. 189-206.

Denzin, N. K. and Lincoln, Y. (2000) Handbook of Qualitative Research (Thousand Oaks, CA: Sage).

Doornbos, A. J., Bolhuis, S. M. and Simons, P. R. J. (2004) Modelling work-related learning on the basis of intentionality and developmental relatedness: a non-educative perspective, Human Resource Development Review, 4, pp. 250-74.

Entwistle, N. J. (1988) Motivational factors in student's approaches to learning, in: R. R. Schmeck (Ed.) Learning Strategies and Learning Styles, pp. 21 -51 (New York: Plenum).

Eraut, M. R. (1998) Development of Knowledge and Skills in Employment (Brighton: University of Sussex Institute of Education, Education Development Building).

Eraut, M. (2000) Non-formal learning and tacit knowledge in professional work, British Journal of Educational Psychology, 70, pp. 113-36.

Faurfelt, K. and Wichmann-Hanssen, G. (1999) The doctor as a counsellor and as a learner: learning processes at a hospital ward, Lifelong Learning in Europe, 4, pp. 25-33.

Fenwick, T. (2001) Tides of change: new themes and questions in workplace learning: new directions for adult and continuing education, in: T. Fenwick (Ed.) Sociocultural Perspectives on Learning through Work, pp. 3-17 (San Francisco, CA: Jossey-Bass). 
Fenwick, T. (2004) Learning in portfolio work: anchored innovation and mobile identity, Studies in Continuing Education, 26, pp. 229-45.

Gear, J., McIntosh, A. and Squires, G. (1994) Informal Learning in the Professions (Hull: School of Education, The University of Hull).

Guba, E. G. and Lincoln, Y. S. (1981) Effective Evaluation: Improving the Usefulness of Evaluation Results through Responsive and Naturalistic Approaches (San Francisco, CA: Jossey-Bass).

Hoeksema, L. H. (1995) Learning strategy as a guide to career success in organizations, dissertation, Universiteit Groningen, Groningen, The Netherlands.

Hoeksema, L. H., van de Vliert, E. and Williams, A. R. T. (1997) The interplay between learning strategy and organizational structure in predicting career success, International Journal of Human Resource Management, 8, pp. 307-27.

Holman, D., Epitropaki, O. and Fernie, S. (2001) Understanding learning strategies in the workplace: a factor analytic investigation, Journal of Occupational and Organizational Psychology, 74, pp. 675-81.

Illeris, K. (2002) The Three Dimensions of Learning: Contemporary Learning Theory in the Tension Field between the Cognitive, the Emotional and the Social (Frederiksberg, Denmark: Roskilde University Press).

Kubo, I., Saka, A. and Pam, S. (2001) Behind the scenes of knowledge sharing in a Japanese bank, Human Resource Development International, 4, pp. 465-85.

Kuhn, T. S. (1962) The Structure of Scientific Revolutions (Chicago, IL: University of Chicago Press).

Lave, J. (1991) Situated learning in communities of practice, in: J. B. Resnick, J. M. Levine and S. D. Teasley (Eds) Perspectives on Socially Shared Cognition, pp. 63 - 83 (Washington, DC: American Psychological Association).

Lincoln, Y. and Guba, E. G. (2000) Paradigmatic controversies, contradictions, and emerging confluences, in: N. K. Denzin and Y. Lincoln (Eds) Handbook of Qualitative Research, pp. 163-88 (Thousand Oaks, CA: Sage).

Marsick, V. J. (2003) Invited reaction: informal learning and the transfer of learning: how managers develop proficiency, Human Resource Development Quarterly, 14, pp. 389-95.

Marsick, V. J. and Watkins, K. E. (1990) Informal and Incidental Learning in the Workplace (London: Routledge).

Marsick, V. J. and Watkins, K. E. (1992) Continuous learning in the workplace, Adult Learning, 3, pp. $9-12$.

Maxwell, J. A. (2002) Understanding and validity in qualitative research, in: A. M. Huberman and M. B. Miles (Eds) The Qualitative Researcher's Companion, pp. 37-64 (Thousand Oaks, CA: Sage).

Megginson, D. (1996) Planned and emergent learning: consequences for development, Management Learning, 27, pp. $411-28$.

Melles, G. (1999) Methodologies in workplace research: relevant paradigms for reform from the inside, Proceedings of the HERDSA Annual International Conference, Melbourne, Australia.

Messick, S. (1980) Test validity and the ethics of assessment, American Psychologist, 35, pp. 1012-27.

Mezirow, J. (1981) A critical theory of adult learning and education', Adult Education, 32, pp. 3-24.

Miles, M. B. and Huberman, A. M. (1994) Qualitative Data Analyses (Thousand Oaks, CA: Sage).

Mintzberg, H. (1970) Structured observation as a method to study managerial work, Journal of Management Studies, 7, pp. 87-104.

Nenninger, P. (1999) On the role of motivation in self-directed learning: the 'two-shells-model of motivated self-directed learning' as a structural explanatory concept, European Journal of Psychology of Education, 14, pp. 71-86.

Noß, M. (2000) Selbstgesteuertes Lernen am Arbeitsplatz (Self-directed Learning at the Worksite) (Wiesbaden: Gabler).

Patton, M. Q. (2002) Qualitative Research and Evaluation Methods (Thousand Oaks, CA: Sage).

Poskiparta, M., Liimatainen, L. and Kettunen, T. (1999) Nurses' self-reflection via videotaping to improve communication skills in health counseling, Patient Education and Counseling, 36, pp. 3-11.

Rainbird, H., Fuller, A. and Munro, A. (2004) Workplace Learning in Context (London: Routledge).

Reimers, A. (1971) Excerpts from a learner's diary or seven months at the Ontario Institute for Studies in Education, Continuous Learning, 10, pp. 2-14.

Rocco, T. S. (2003) Shaping the future: writing up the method on qualitative studies, Human Resource Development Quarterly, 14, pp. 343-49. 
Russ-Eft, D., Burns, J. Z., Dean, P. J., Hatcher, T. G., Otte, F. L. and Preskill, H. S. (1999) $A H R D$ Standards on Ethics and Integrity, 1st ed. (Academy of Human Resource Development).

Selmes, I. (1987) Improving Study Skills (London: Hodder \& Stoughton).

Smith, P. J. (2003) Workplace learning and flexible delivery, Review of Educational Research, 7, pp. 53 - 88. Stevens, P. A. (1997) Using concept maps for assessing adult learners in training situations, Dissertation, University of New Mexico, Albuquerque, New Mexico.

Straka, G. A. (2003) Modeling a more-dimensional theory of self-directed learning, in: G. A. Straka (Ed.) Conceptions of Self-Directed Learning, pp. 171-90 (Munster: Waxmann).

Tough, A. (1971) The Adult's Learning Projects, Research in Education Series No. 1 (Toronto: Ontario Institute for Studies in Education).

Valkevaara, T. (2002) Exploring the construction of professional expertise in HRD: analysis of four HR developers' work histories ad career stories, Journal of European Industrial Training, 26, pp. 183 -95.

van Woerkom, M. (2003) Critical reflection at work: bridging individual and organisational learning, dissertation, Twente University, Enschede, The Netherlands.

Warr, P. and Downing, J. (2000) Learning strategies, learning anxiety and knowledge acquisition, British Journal of Educational Psychology, 91, pp. 311-33.

Wheelan, S. A., McKeage, R. L., Verdi, A. F., Abraham, M., Krasick, C. and Johnston, F. (1994) Communication and developmental patterns in a system of interacting groups, in: L. R. Frey (Ed.) Group Communication in Context: Studies of Natural Groups, pp. 153-78 (Hillsdale, NJ: Lawrence Erlbaum).

Yin, R. K. (1994) Case Study Research: Design and Methods, 2nd ed. (Newbury Park, CA: Sage). 


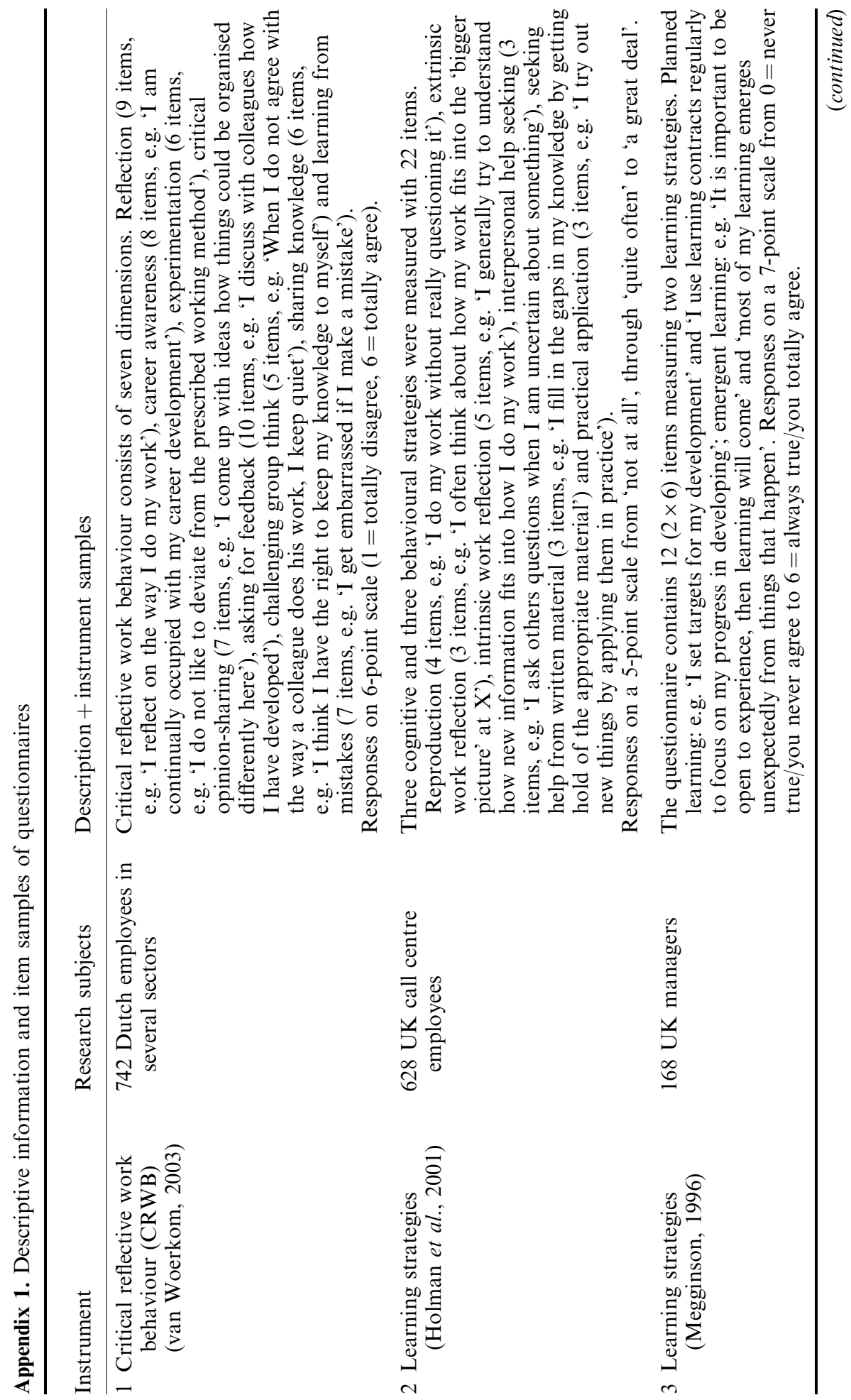




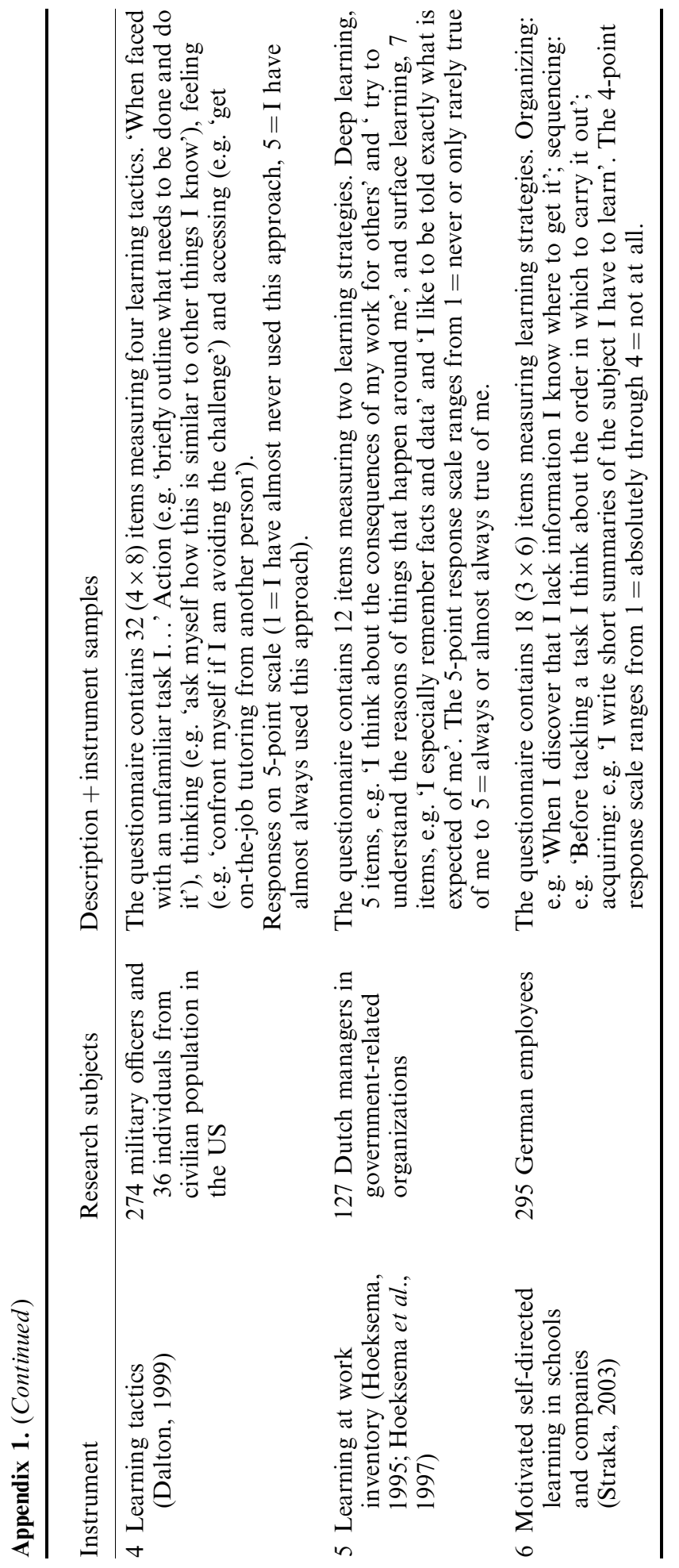


M. G. M. C. Berings et al.

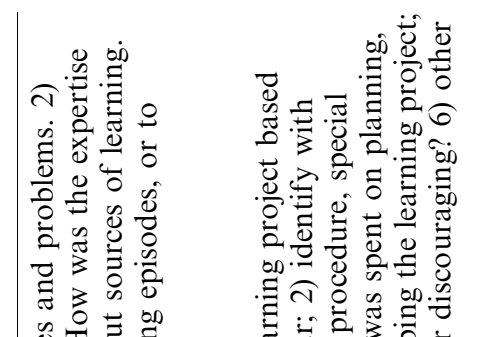

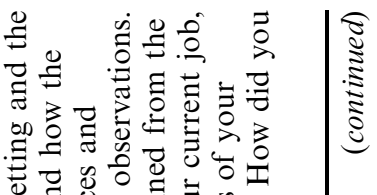

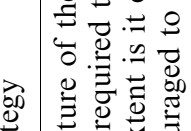

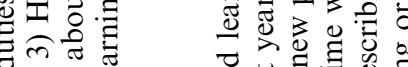

की

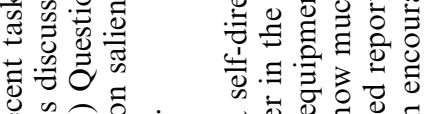

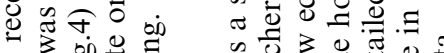

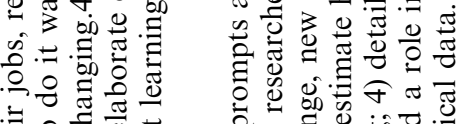

월

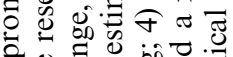

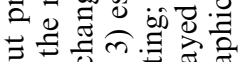

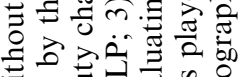

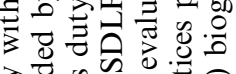

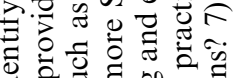

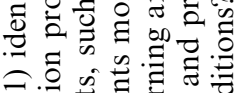

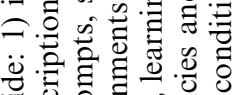

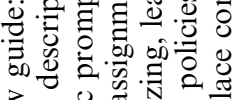

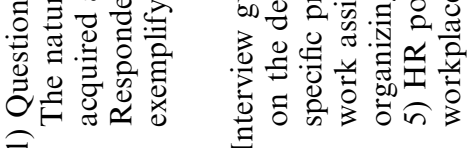

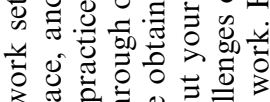

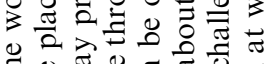

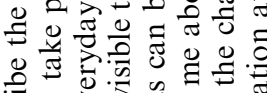

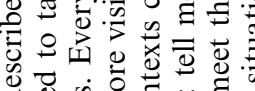

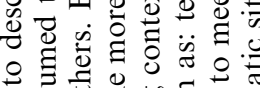

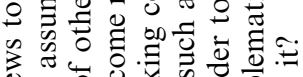

क人

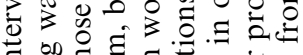

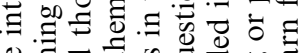

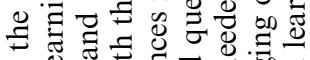

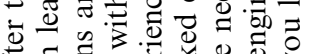

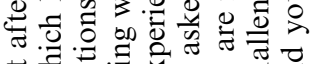

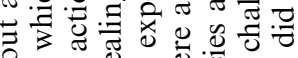

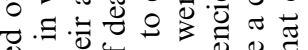

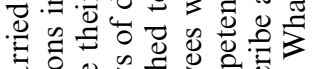

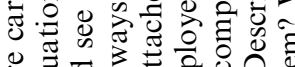

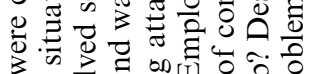

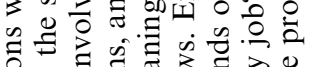

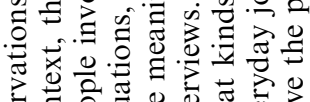

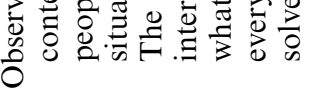

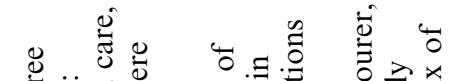

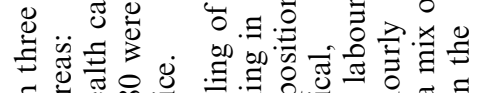

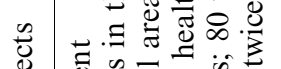

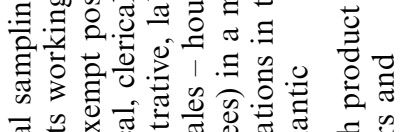

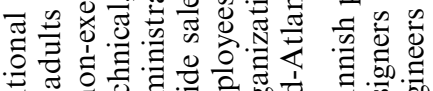

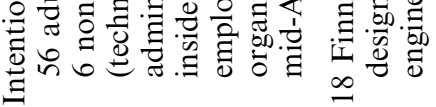

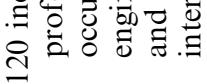

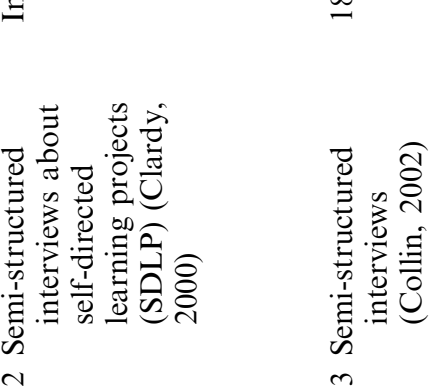


Methodological Practices in On-the-Job Learning Research 363

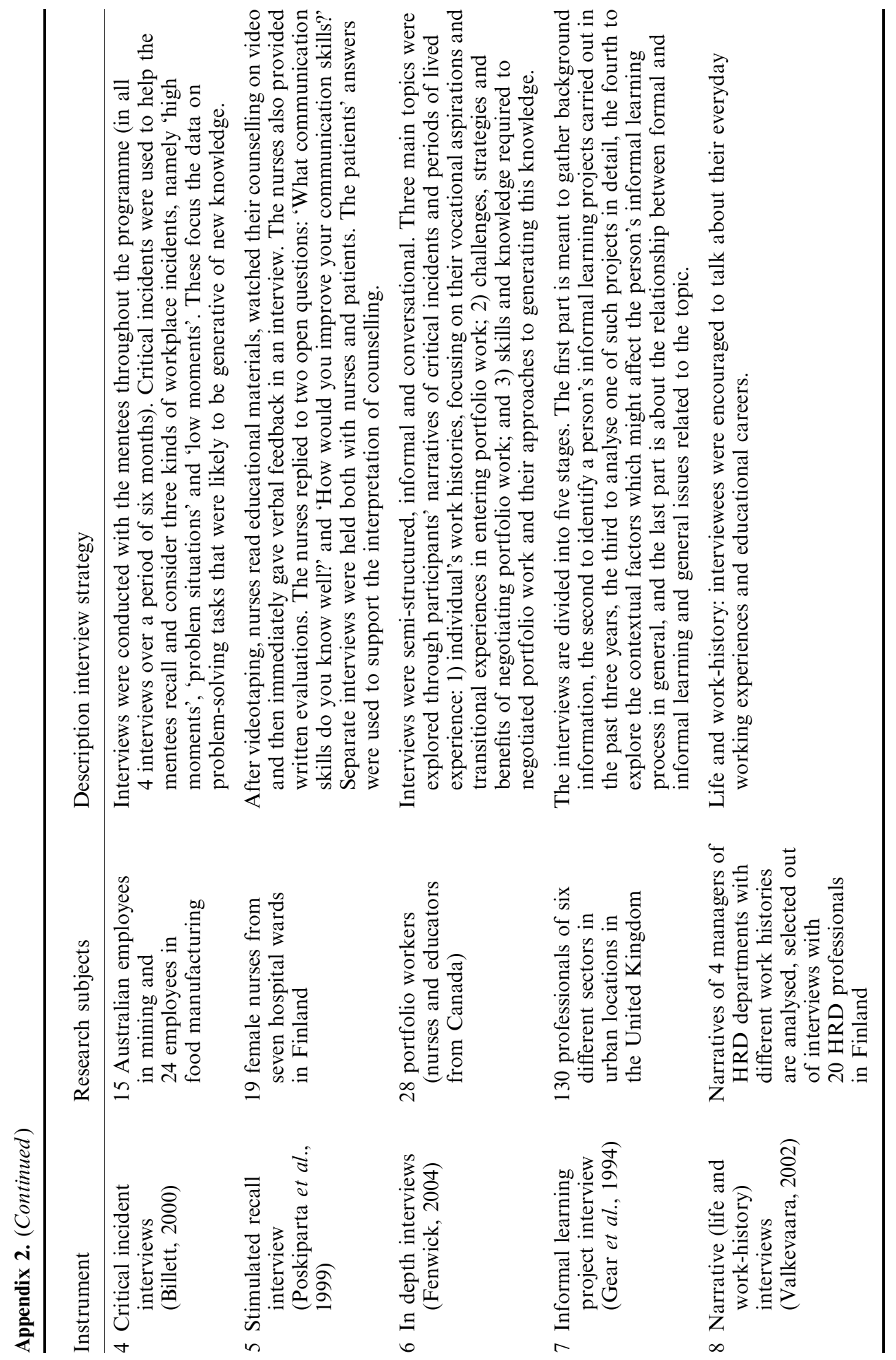

